\title{
Chronic prenatal hypoxia impairs cochlear development, a mechanism involving connexin 26 expression and promoter methylation
}

\author{
JINGCANG LIN ${ }^{1}$, HUANG HUANG ${ }^{2}$, GUORONG LV $^{3}$, XIANGYANG XU $^{2}$, WENDONG LIN $^{4}$, \\ XIANYAN XU ${ }^{4}$, JING CHENG $^{2}$ and MING ZHENG ${ }^{1}$ \\ ${ }^{1}$ Department of Anatomy, School of Basic Medical Sciences, Fujian Medical University, Fuzhou, Fujian 350004; \\ Departments of ${ }^{2}$ Histology and Embryology, ${ }^{3}$ Medical Imaging and ${ }^{4}$ Anatomy, \\ Quanzhou Medical College, Quanzhou, Fujian 362100, P.R. China
}

Received July 12, 2017; Accepted November 2, 2017

DOI: $10.3892 /$ ijmm.2017.3303

\begin{abstract}
Chronic prenatal hypoxia is a damaging to fetal development and may have various consequences, including hearing loss. Connexin 26 (Cx26) is one of the major protein subunits required for gap junction formation, and has an important role in maintaining homeostasis in the cochlea and normal hearing. Cx26 mutation and expression abnormality are closely associated with inherited nonsyndromic deafness, but the association between Cx26 and prenatal hypoxia is less established. The present study aimed to examine Cx26 expression and aberrant methylation the $\mathrm{Cx} 26$ promoter region in the cochlea from rats exposed to chronic prenatal hypoxia. Hematoxylin and eosin staining demonstrated that the number of hair cells in the organ of Corti were less in the hypoxia group. Reverse transcription-quantitative polymerase chain reaction and western blot analysis revealed that protein and mRNA levels of Cx26 were decreased in the hypoxia group compared with the control group. Further bisulfite sequencing analysis revealed that prenatal hypoxia significantly increased the methylation status of the promoter region of the Cx26 gene. These results demonstrate that chronic prenatal hypoxia caused hearing impairment, and suggest that promoter region hypermethylation and expression downregulation of $\mathrm{Cx} 26$ underlie the mechanism of action.
\end{abstract}

\section{Introduction}

Deafness is a serious event that impacts human health. Maintenance of normal hearing and cochlear function requires adequate oxygenation and perfusion (1). Hypoxia, especially chronic hypoxia, e.g. long-term living in special environ-

Correspondence to: Dr Ming Zheng, Department of Anatomy, School of Basic Medical Sciences, Fujian Medical University, 88 Jiaotong Road, Fuzhou, Fujian 350004, P.R. China

E-mail: zhengmingdoctor@126.com

Key words: connexin 26, gap junction $\beta 2$, fetal, hearing, hypermethylation, hypoxia ment, such as the highlands, has an evident detrimental effect on cochlear function and hearing sensitivity (2). Hypoxia in neonates with inadequate blood-inner ear barrier function causes damage to the inner ear more easily than in adults, leading to hearing loss and equilibration disorder (3). Intrauterine hypoxia at the prenatal stage leads to severe damage during fetal development. Intrauterine hypoxia is a common environmental stressor caused by maternal (smoking, environmental pollutants), placental (placental insufficiency) or fetal factors (anemia, cardiac defects) (4). Depending on the severity of the hypoxic insult, affected fetuses will have varying degrees of injury, from alterations in metabolic, endocrine and hematological systems, to overt tissue necrosis in the most severe settings, including reversible or irreversible injury in the cochlea and hearing loss (5-7).

Among the factors involved in hearing loss at the fetal and natal stages, connexin 26 (Cx26), which is coded by gap junction protein $\beta 2$ gene, is considered to have an important role in maintaining normal hearing. Connexins are components of gap junctions that facilitate the transfer of small molecules between cells. Cx26, one member of the connexin family, is present in gap junctions in the sensory epithelia of the inner ear (8). Cx26 mutations are one of the most common causes of inherited nonsyndromic deafness $(8,9)$, presbycusis $(10)$, and other disease types, including skin disorders (11). In various hearing loss models, Cx26 was frequently observed at low expression levels in inner ear tissues $(12,13)$ and the recovery of Cx26 was beneficial to hearing loss (14). It is less well-established how Cx26 expression is changed and regulated in the inner ear. A variety of putative post-translational modifications of Cx26 have been identified, including acetylation, hydroxylation, $\gamma$-carboxyglutamation, methylation and phosphorylation, some of which occur at sites of deafness-causing mutations (11). As methylation of the cytosine residues at $\mathrm{CpG}$ dinucleotides of the promoter region is reported to lead to transcriptional silencing of many genes $(15,16)$, hypermethylation of the $\mathrm{CpG}$ sites of promoter region of the $\mathrm{Cx} 26$ gene was also reported in the cochlea of inner ear, and was considered to be a cause of Cx26 expression downregulation (12). In tissues other than ear, the Cx26 expression level is inversely correlated with the status of methylation. Cx26 expression was decreased, which 
was accompanied by the hypermethylation of the 5 ' upstream region of this gene in rat lung adenocarcinomas, colorectal cancer and hepatocellular carcinomas (17-19). Currently, the association between hearing loss from chronic prenatal hypoxia and $\mathrm{Cx} 26$ expression and regulation is less reported. Thus, the aim of the current study was to investigate the expression level of $\mathrm{Cx} 26$ and the $\mathrm{CpG}$ methylation status of the promoter region in the cochlea of newborn rats that were exposed to chronic intermittent maternal hypoxia.

\section{Materials and methods}

Animals. All experimental procedures were performed in accordance with National Institutes of Health guidelines, and approved by the Standing Committee on Ethics and Animal Experimentation at the Fujian Medical University (Fujian, China). Virgin female Sprague-Dawley rats used in this study were obtained from the Shanghai Experimental Animal Center (Shanghai, China). They were housed under controlled temperature $\left(22 \pm 1^{\circ} \mathrm{C}\right)$, humidity $(50 \pm 10 \%)$, fresh air $(100 \%)$ and light conditions (lights on from 7:00 am to 7:00 pm). Food and water were freely available. For breeding, 3-month-old females were caged with males of the same strain (rate 2:1). The vaginal smears were checked each morning for the presence of spermatozoa. Pregnancy was confirmed by sperm-positive vaginal smear (day 0). On day 7, the pregnant rats were randomly assigned to control and maternal hypoxia groups ( $\mathrm{n}=6$ each; 12 rats in total; weighing prior to breeding 25-30 g).

Chronic prenatal hypoxia. Chronic prenatal hypoxia was performed by chronic maternal intermittent hypoxia $(20,21)$, which was initiated on day 7 of gestation until delivery day (once daily; 14 days). Pregnant rats in the hypoxia group were placed in a plexiglass chamber (140 L, volume), which was continuously infused with nitrogen and compressed air to maintain an oxygen concentration of $12 \pm 1 \%$. Oxygen concentration in the chamber was monitored using a portable gas analyzer, which was calibrated daily. The expired $\mathrm{CO}_{2}$ was eliminated by circulating the atmosphere through soda lime, and the water contained in the expired gas was trapped in a chilled glass tank. Rats were back to normal room air after $8 \mathrm{~h}$ of hypoxia. Food and water were freely available during hypoxia. Normoxic control rats were placed into an identical plexiglass chamber, into which only compressed air, but no nitrogen was continuously infused. They underwent the same procedures as the animals exposed to hypoxia. On day 1 of hypoxia administration, arterial blood samples were withdrawn from the cannulated femoral artery after $1 \mathrm{~h}$ of hypoxia for the measurement of blood gas and $\mathrm{pH}$ by a blood gas analyzer (Rapidlab 850; Bayer AG, Leverkusen, Germany).

Deafness screening in offspring rats. Offspring rats $(n=120 ; 60$ per group) were tested for auditory brainstem response (ABR) in the first week following birth. Acoustic stimulation and recordings were performed with an Auditory Evoked Potential Workstation (ICS ChartR EP 200; Otometrics A/S, Copenhagen, Denmark). Briefly, animals were located in a double shielded booth and were placed inside a sound-attenuating room. Rats were anesthetized with $10 \%$ chloral hydrate $(300 \mathrm{mg} / \mathrm{kg})$ by intraperitoneal injection. Recording electrodes were placed at the crossing of the sagittal median of calvaria and the line of bilateral external ears. Electrode needles were penetrated $0.5 \mathrm{~cm}$ into the subderma. Reference electrodes were placed subcutaneously at bilateral retroauricular areas. Ground electrodes were placed at the nasal root. Electrodes resistance was set at $<3 \mathrm{~K} \Omega$. The parameters of click sound stimuli included cycle $100 \mu \mathrm{sec}$, velocity 21.1 , scan time $15 \mathrm{msec}$, range of wave filter $100-3,000 \mathrm{~Hz}$, supraposition 1,024 times. Testing started from auditory stimulus of $100 \mathrm{~dB}$ sound pressure level (SPL), which descended in $5 \mathrm{~dB}$ SPL increments until wave III disappeared. The dB SPL value when wave III disappeared was set as the ABR threshold. All offspring rats received ABR test. Deafness was confirmed when the ABR threshold was $\geq 15 \mathrm{~dB}$ on at least one ear.

Hematoxylin and eosin $(H \& E)$ staining. The cochleae from 56-day-old offspring were extracted for H\&E staining $(n=6)$. The cochleae were dissected immediately from the auditory vesicles upon sacrifice. Tissues were fixed with $4 \%$ paraformaldehyde overnight at $4^{\circ} \mathrm{C}$, decalcified with $10 \%$ EDTA $1 \mathrm{~h}$ at room temperature, dehydrated with a graded series of ethanol $(100,90$, 80 and $70 \%, 5$ min each step) at room temperature, cleared in xylene for $10 \mathrm{~min}$ at room temperature, and embedded in paraffin. Sections were cut at a thickness of $3 \mu \mathrm{m}$ and stained with $\mathrm{H} \& \mathrm{E}$ containing $0.1 \%$ eosin B and $0.7 \%$ Hematoxylin solution.

Western blot analysis. The cochleae from 56-day old offspring were used to examine $\mathrm{Cx} 26$ protein expression with western blot analysis. The cochlear tissues were homogenized in radioimmunoprecipitation assay lysis buffer (Sigma-Aldrich, St. Louis, MO, USA). Homogenates were centrifuged at 10,000 x g at $4^{\circ} \mathrm{C}$ for $5 \mathrm{~min}$, and the soluble protein content of the supernatant was determined with a bicinchoninic acid protein assay kit (Xiamen Bioluminor Bio-Technology Co., Ltd., Xiamen, China). A total of $30 \mu \mathrm{g}$ total protein was electrophoretically separated using 4-12\% SDS-PAGE gels and then transferred to nitrocellulose membranes. Following 30 min of blocking with $2.5 \%$ skimmed milk at room temperature, the membranes were incubated with rabbit anti-Cx26 polyclonal antibody (1:1,000; cat. no. sc-130729) or rabbit anti- $\beta$-actin polyclonal antibody (1:5,000; cat.no. sc-130656; both from Santa Cruz Biotechnology, Inc., Dallas, TX, USA) overnight at $4^{\circ} \mathrm{C}$, followed by $1 \mathrm{~h}$ incubation with a horseradish peroxidase-conjugated goat anti-rabbit immunoglobulin secondary antibody (1:2,000; cat. no. sc-2004; Santa Cruz Biotechnology, Inc.). Following treatment with each antibody, the membranes were washed with phosphate-buffered saline containing 0.5\% Tween-20 (Sigma-Aldrich; Merck KGaA, Darmstadt, Germany). Proteins on the membranes were visualized using enhanced chemiluminescence reagents (Pierce; Thermo Fisher Scientific, Inc., Waltham, MA, USA) and then exposed to X-ray film. The intensity of bands was analyzed with Quantity One v4.62 analyzer software (Bio-Rad Laboratories, Inc., Hercules, CA, USA). The protein levels are expressed as the ratio of the band optical intensity to that of $\beta$-actin.

Reverse transcription-quantitative polymerase chain reaction (RT-qPCR). RT-qPCR was performed to measure the mRNA expression of $\mathrm{Cx} 26$. The cochleae of 56-day old offspring were dissected immediately from the auditory vesicles upon sacrifice. Total RNA was extracted using TRIzol reagent (Life Technologies; Thermo Fisher Scientific, Inc.). The RNA (5 $\mu \mathrm{g})$ 
Table I. Arterial blood gas analysis of maternal rats.

\begin{tabular}{lcccc}
\hline Group & $\mathrm{PaO}_{2}(\mathrm{kPa})$ & $\mathrm{SaO}_{2}(\%)$ & $\mathrm{PaCO}_{2}(\mathrm{kPa})$ & $\mathrm{pH}$ \\
\hline Control & $11.17 \pm 2.68$ & $92.6 \pm 3.0$ & $6.21 \pm 1.15$ & $7.4 \pm 1.0$ \\
Hypoxia & $7.19 \pm 2.75^{\mathrm{a}}$ & $75.3 \pm 3.4^{\mathrm{a}}$ & $5.98 \pm 2.17$ & $7.3 \pm 2.2$ \\
\hline
\end{tabular}

${ }^{\mathrm{a}} \mathrm{P}<0.05$ vs. control group. $\mathrm{n}=6$ per group. $\mathrm{PaO}_{2}$, arterial $\mathrm{O}_{2}$ partial pressure; $\mathrm{SaO}_{2}$, oxygen saturation; $\mathrm{PaCO}_{2}$, arterial $\mathrm{CO}_{2}$ partial pressure.

Table II. Body weight of offspring at different time points after birth.

\begin{tabular}{lccc}
\hline & $12 \mathrm{~h}$ & 21 days & 56 days \\
\hline Control $(\mathrm{n}=60)$ & $6.0 \pm 0.4$ & $52.4 \pm 3.0$ & $302.3 \pm 11.0$ \\
Hypoxia $(\mathrm{n}=60)$ & $4.8 \pm 0.6^{\mathrm{a}}$ & $58.8 \pm 9.0$ & $306.6 \pm 21.0$ \\
\hline
\end{tabular}

${ }^{\mathrm{a}} \mathrm{P}<0.05$ vs. control group.

was reverse transcribed into cDNA using SuperScript II reverse transcriptase (Invitrogen; Thermo Fisher Scientific, Inc.) and random hexonucleotide primers $(0.1 \mu \mathrm{g}$ random hexonucleotide primer and $10 \mathrm{pmol} \mathrm{dNTP)} \mathrm{at} 65^{\circ} \mathrm{C}$ for $5 \mathrm{~min}$ and incubated for $1 \mathrm{~h}$ at $37^{\circ} \mathrm{C}$. qPCR was performed with an iCycler using SYBR Premix Ex Taq (Takara Biotechnology Co., Ltd., Dalian, China). Results are presented as the levels of expression relative to those of the controls subsequent to normalize to $\beta$-actin using the $2^{-\Delta \Delta C q}$ method (22). The PCR process was as follows: first, an initial denaturation was realized at $94^{\circ} \mathrm{C}$ for $5 \mathrm{~min}$, then 39 cycles were performed with the following cycling profile: denaturation at $94^{\circ} \mathrm{C}$ for $30 \mathrm{sec}$, annealing at $54^{\circ} \mathrm{C}$ for $30 \mathrm{sec}$ and extension at $68^{\circ} \mathrm{C}$ for $30 \mathrm{sec}$ each. The primer sequences for PCR were as follows: Cx26 sense, 5'-ACCACTACTTCCCCA TCTCT-3' and antisense, 5'-TCGTTCTTTATCTCTCCC TTC-3'; $\beta$-actin sense, 5'-GGCTCTCTGCTCCTCCC-3' and antisense, 5'-CCGTTCACACCGACCTT-3'.

Bisulfite sequencing. The evaluation of $\mathrm{CpG}$ site methylation of the promoter region of Cx 26 gene was performed by bisulfite sequencing according to previous descriptions $(12,23,24)$. The cochleae of 56-day old offspring were obtained from the auditory vesicles immediately upon sacrifice. Genomic DNA was extracted using a genomic DNA purification kit (Tiangen Biotech Co., Ltd., Beijing, China) according to the manufacturer's instructions. The purified DNA was bisulfate treated using EZ DNA Methylation-Gold kit (Zymo Research Corp., Irvine, CA, USA). Previous publications documented that two target $\mathrm{CpG}$ islands, fragment 1 and 2 , are present in the promoter region of Cx26 $(12,23,24)$. The two regions were then amplified by PCR using TaKaRa Ex Taq (Takara Biotechnology Co., Ltd.) with the following primers: Fragment 1 sense, 5'-TTTTTGGTATTTTGTTTAAAG TGAT-3' and antisense, 5'-ATATAAACCAACAACTTCCAA TATC-3'; fragment 2 sense, 5'-GGAGTGATTTAGGTTTTA GGAGAG-3' and antisense, 5'-TCCCCACAAATCCTAATA AAAACTAC-3'. PCR products were purified and then were

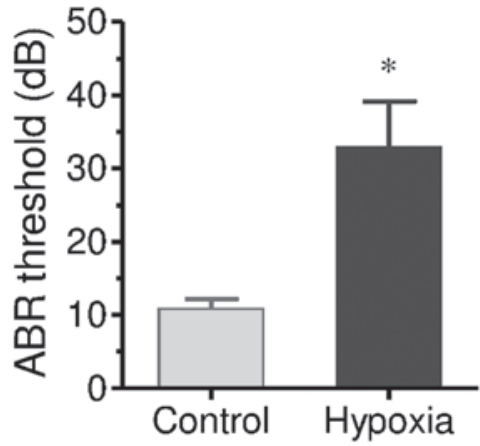

Figure 1. Hearing ABR analysis in offspring. ABR testing was performed on all offspring rats at 1 week after birth. The ABR threshold was recorded $(n=60$ per group). ${ }^{*} \mathrm{P}<0.01$ vs. control group. ABR, auditory brainstem response.

inserted into pMD19-T Simple Vector (Takara Biotechnology Co., Ltd.) and transformed to competent Escherichia coli DH5 $\alpha$ (Beijing Transgen Biotech Co., Ltd., Beijing, China). The consequent recombinant plasmids were extracted with TIANprep mini plasmid extraction kit (Tiangen Biotech Co., Ltd.). The extracted plasmids were sequenced to analyze the status of DNA methylation (Tsingke Biotech Co., Wuhan, China). Methylation level was expressed as the ratio of methylated $\mathrm{CpG}$ sites to the total $\mathrm{CpG}$ site number in fragments 1 and 2 .

Statistical analysis. Data re presented as the mean \pm standard error. The unpaired Student's two-tailed t-test was used for comparing two groups. All data analyses were performed using SPSS 11.5 (SPSS, Inc., Chicago, IL, USA). P<0.05 was considered to indicate a statistically significant difference.

\section{Results}

Arterial blood gas analysis. At day 1 of hypoxia, arterial blood was withdrawn from cannulated femoral artery of maternal rats after $1 \mathrm{~h}$ of hypoxia for blood gas analysis. The results showed that arterial $\mathrm{O}_{2}$ partial pressure and oxygen saturation were significantly decreased in the hypoxia group compared with the control group. There were no significant differences in mean arterial $\mathrm{CO}_{2}$ partial pressure and $\mathrm{pH}$ value between the two groups (Table I). These results indicate that there was hypoxemia without $\mathrm{CO}_{2}$ retention and acidosis in the hypoxia group, and suggest a reliable hypoxia animal model.

Chronic maternal hypoxia results in intrauterine growth restriction of offspring. Every maternal rat in the two groups gave birth to 12-13 pups. The body weight of offspring was recorded following birth. The data showed that the body weight at neonatal stage (12 $\mathrm{h}$ after birth) was significantly lower in the hypoxia group than in the control group (Table II). At later time-points, 21 and 56 days, there was no significant difference in body weight between the two groups, although the body weight of the hypoxia group was a marginally more than in the control group. Thus, these results suggest that chronic maternal hypoxia caused a significant intrauterine growth restriction of offspring.

Chronic maternal hypoxia causes hearing dysfunction in offspring. ABR testing was performed on newborn rats 1 week after delivery. In the offspring rats from the control group, 


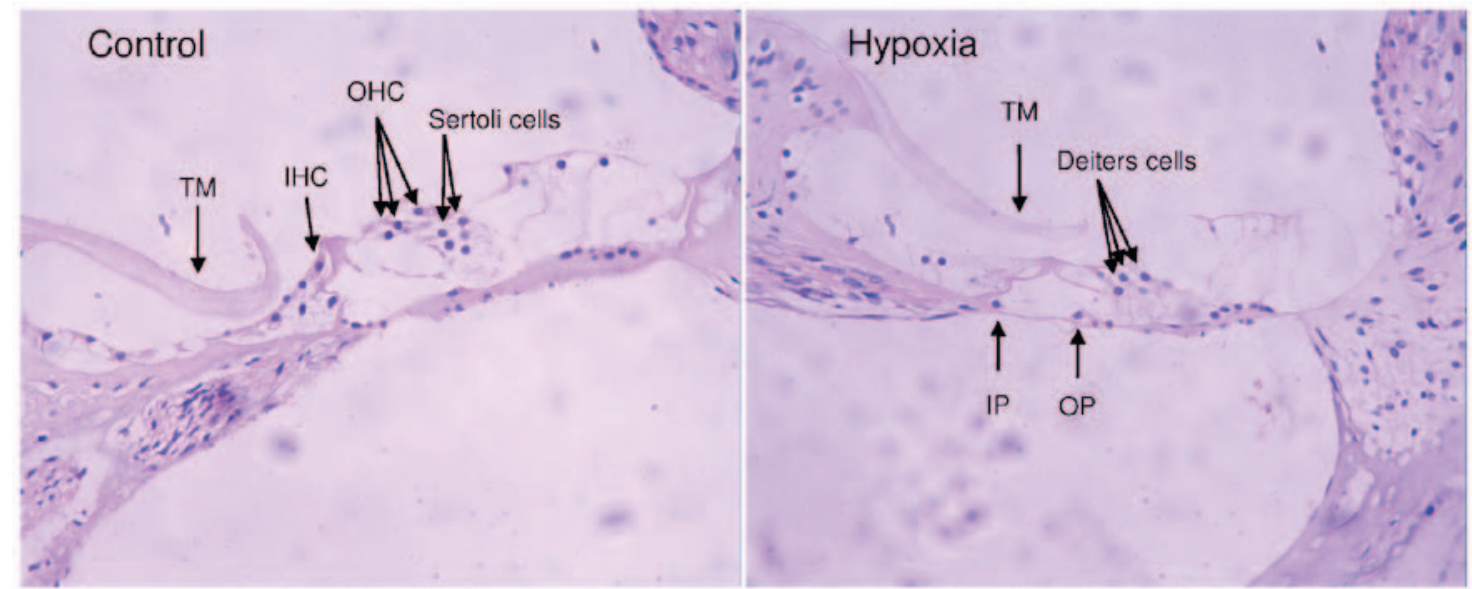

Figure 2. H\&E staining of cochlea of offspring. The cochlear tissues of 56-day-old offspring from normoxic control and chronic maternal hypoxia (hypoxia) groups were extracted for H\&E staining (x400, n=10). H\&E, hematoxyline and eosin, TM, tectorial membrane; IHC, inner hair cells; OHC, outer hair cells; OP, outer pillar cell; IP, inner pillar cell.
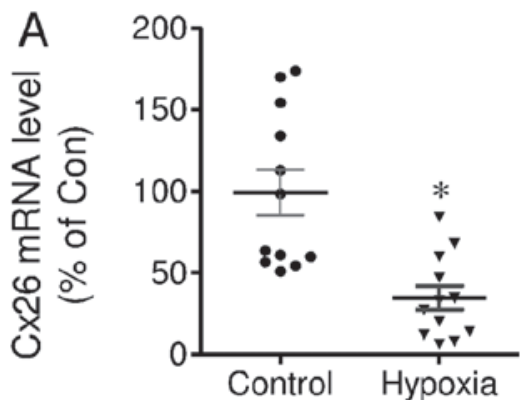

B

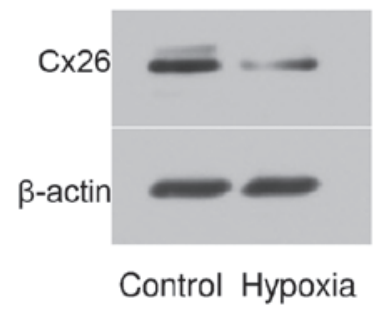

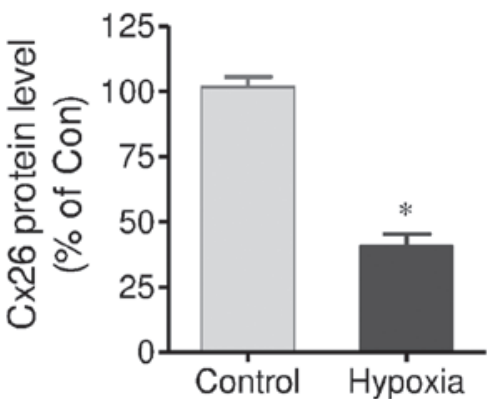

Figure 3. mRNA and protein expression of Cx26 in cochlear tissues of offspring. The cochlear tissues of offspring at 56-days-old from normoxic control and chronic maternal hypoxia (hypoxia) groups were used to measure (A) mRNA expression with reverse transcription-quantitative polymerase chain reaction $(n=12)$, and (B) protein expression with western blot analysis $(n=12)$. The protein levels are expressed as the ratio of optical intensity of $C x 26$ to that of $\beta$-actin. Representative immunoblots are shown to the left of the semi-quantified data. ${ }^{*} \mathrm{P}<0.05$ vs. control group. Cx 26 , connexin 26.

only one rat exhibited hearing dysfunction. The mean ABR threshold was $10.84 \mathrm{~dB}$. This deaf rat was excluded in further testing. In the offspring rats from the hypoxia group, 28 rats were confirmed as deaf. ABR threshold (mean threshold) was $32.45 \mathrm{~dB}(\mathrm{P}<0.01$; Fig. 1). This indicates that chronic maternal hypoxia effectively caused offspring hearing dysfunction. The normal hearing rats were excluded, and only the deaf offspring rats in the hypoxia group were used in further studies.

Effect of chronic prenatal hypoxia on cochlear development. The effect of chronic prenatal hypoxia on cochlear development was examined with H\&E staining (Fig. 2). In offspring from both groups, no cellular degeneration in cochlear nerve and the spiral ganglion was observed. There was no inflammatory cell infiltration in the organ of Corti, and the stria vascularis was clear. In the organ of Corti of the offspring from control group, sporadic inner hair cells, outer hair cell and sertoli cells were observed. In the hypoxia group, only Deiters cells, and some inner pillar cells and outer pillar cells were observed in organ of Corti, however no inner and outer hair cells were observed. These results indicate chronic prenatal hypoxia caused marked abnormal cochlear development.

Effect of chronic prenatal hypoxia on Cx26 mRNA and protein expression in cochlear tissues. The effects of hypoxia on Cx26 mRNA and protein expression in the cochleae of offspring were measured by RT-qPCR and western blot analysis, respectively. The results demonstrated that $\mathrm{Cx} 26$ mRNA expression in the hypoxia group was significantly decreased, compared with control group. The mean value in the hypoxia group was $34.73 \%$ of control group (Fig. 3A). Similarly, Cx26 protein expression was also significantly decreased in the hypoxia group, and it was $40.85 \%$ of the control group (Fig. 3B). These results demonstrate chronic prenatal hypoxia negatively regulates Cx26 expression in cochlear tissues.

$C p G$ site methylation of the promoter region of $C \times 26$ gene in cochlear tissues. $\mathrm{CpG}$ site methylation of the promoter region of $\mathrm{Cx} 26$ (including fragment 1 and 2) in cochlear tissues of offspring exposed to hypoxia in utero was measured by bisulfite sequencing PCR (Figs. 4 and 5). As shown in Fig. 4, many methylation sites were detected in fragment 1 of the promoter region of $\mathrm{Cx} 26$. The methylation ratio was up to $26.7 \%$ in the control group. Chronic maternal hypoxia increased the methylation ratio to $42.8 \%$ ( $\mathrm{P}<0.01$ vs. control). In fragment 2 (Fig. 5), although a low methylation ratio (4.3\%) of the promoter region of $\mathrm{Cx} 26$ was observed in the control group, a significantly higher methylation ratio was detected in the hypoxia group $(11.8 \%$; $\mathrm{P}<0.01)$. These results demonstrate 

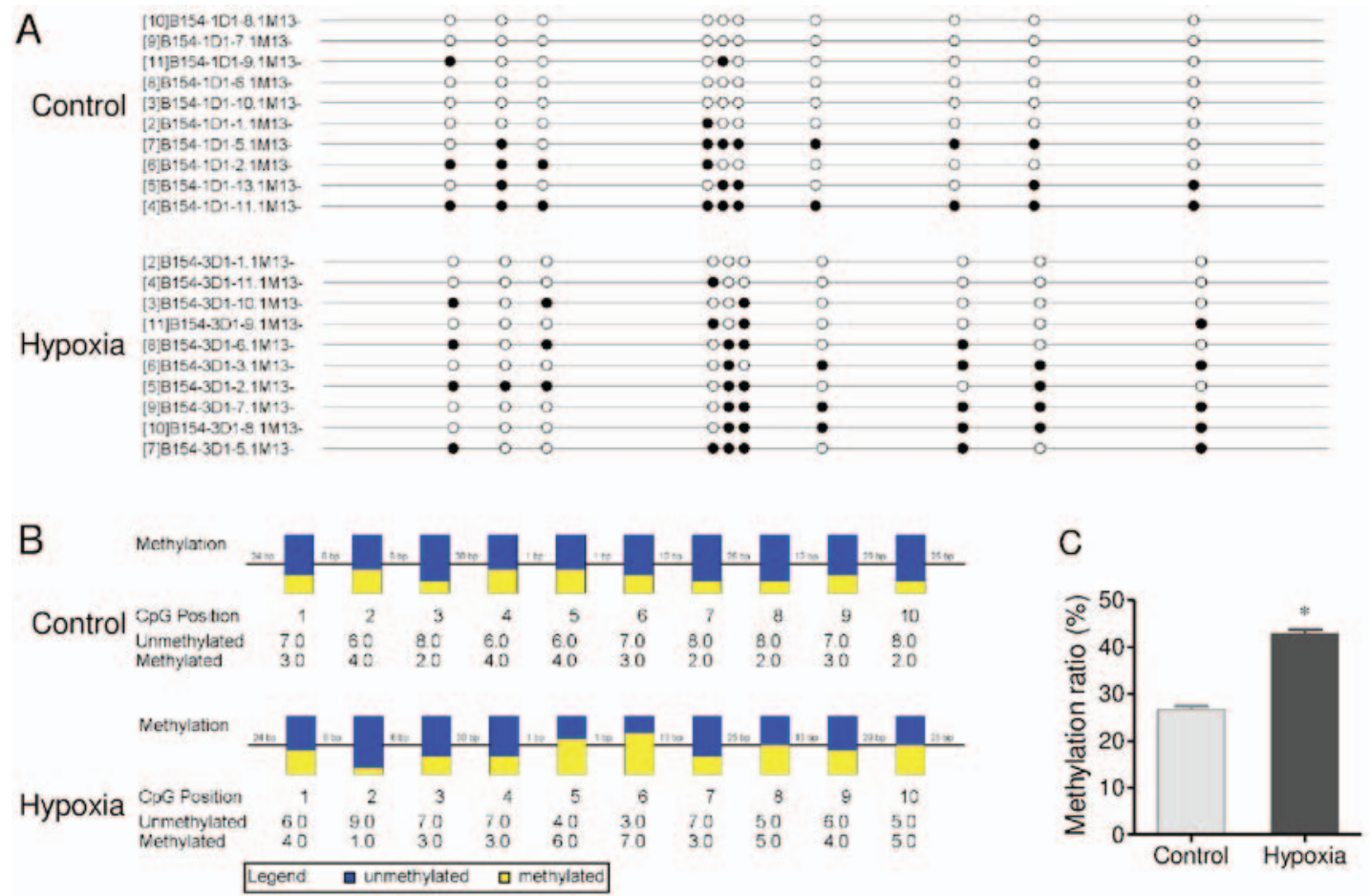

Figure 4. Bisulfite sequencing of fragment 1 of the promoter region of Cx26 gene in cochlear tissues of offspring rats. The cochlear tissues of rats at 56 days old age from the normoxic control and chronic maternal hypoxia groups were used to measure fragment 1 of the promoter region of Cx26 gene with bisulfite sequencing polymerase chain reaction $(\mathrm{n}=6)$. (A) Representative sequencing diagrams, (B) the subsequently summarized data and $(\mathrm{C})$ total methylated $\mathrm{CpG}$ rates are shown. Methylation is indicated by closed circles and unmethylated $\mathrm{CpGs}$ are indicated as open circles. ${ }^{*} \mathrm{P}<0.001$ vs. control group. Cx26, connexin 26.

A

\section{Control}

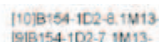
1918154 102-7 w13 17]8154 102.5 1913

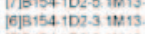
$158154+02-21213.13$. $[4] \mathrm{B} 154+102-12.1 \mathrm{M13}$ [318154 102-11:1413. $[2] 18154: 102+4,1013$.

$213154.302-1,1913$ 19815154302-7 1913 $778154.902 .5+1913$.

Hypoxia

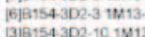

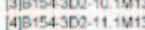

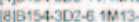
$1518154302-12.1 \mathrm{M}:$

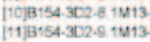
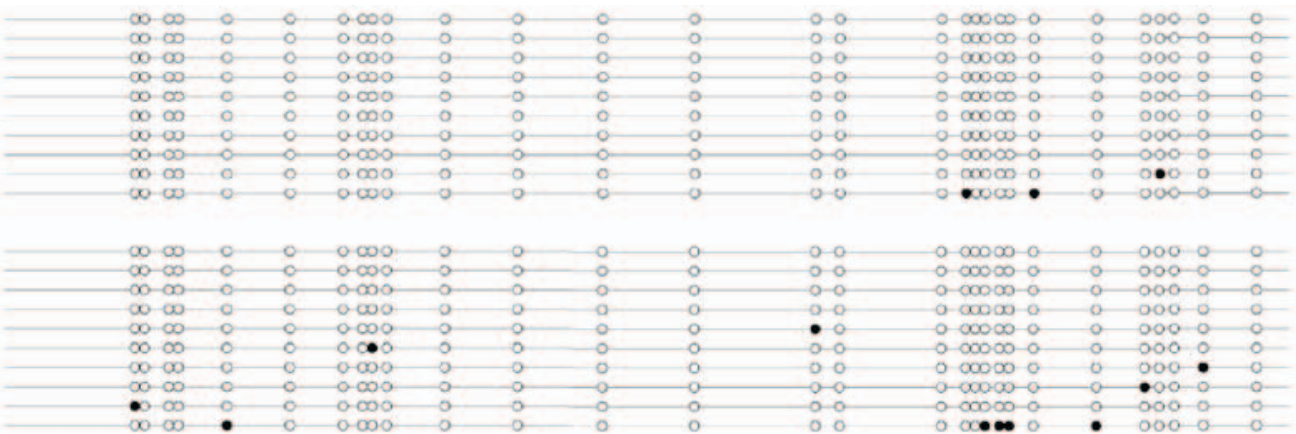

B

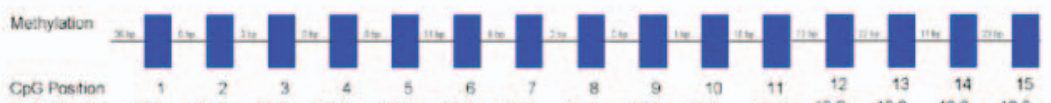

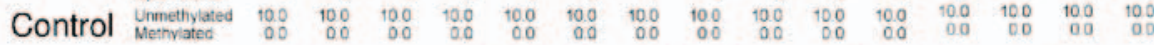

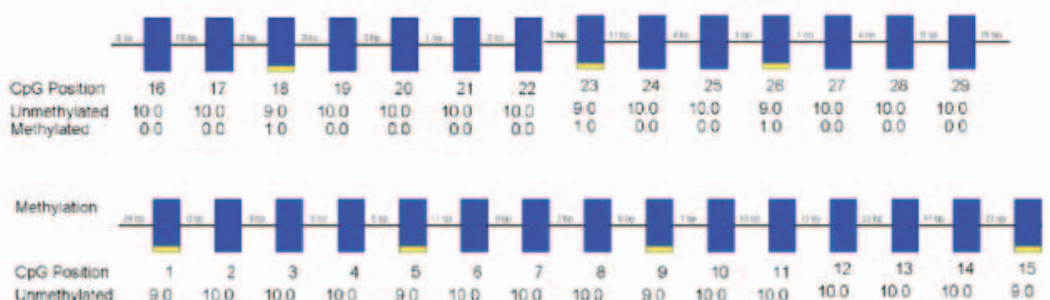

CDG Postion

90000

10

Hypoxia Linmethylated
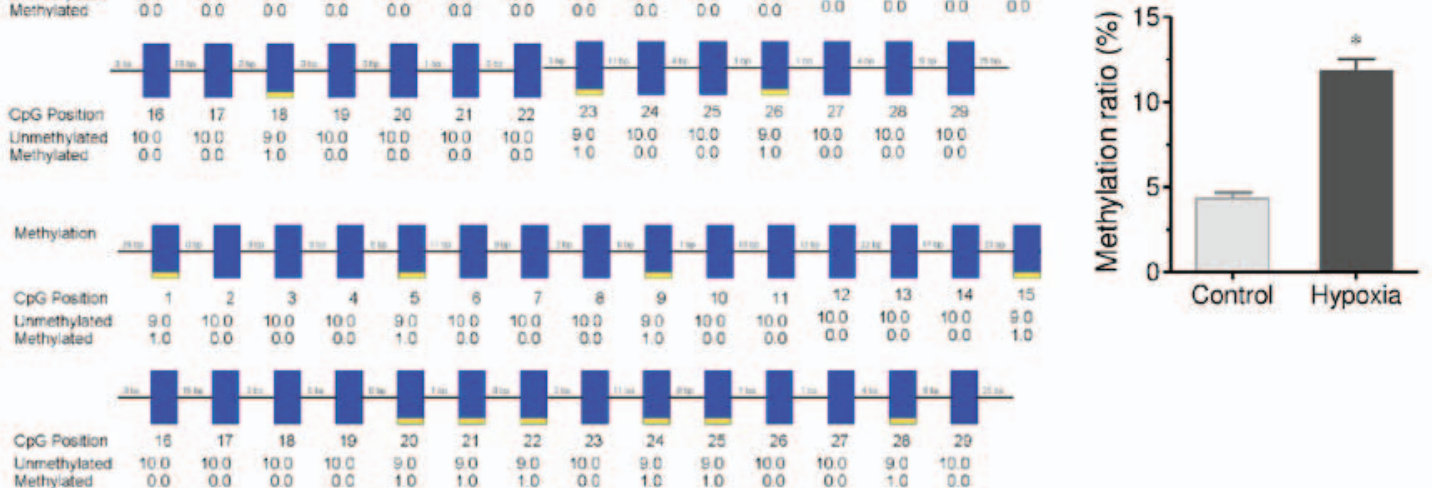

Legend a unmethylated a methylated

Figure 5. Bisulfite sequencing of fragment 2 of the promoter region of Cx 26 gene in cochlear tissues of offspring. The cochlear tissues of offspring at 56 day old from normoxic control and chronic maternal hypoxia groups were used to measure fragment 2 of the promoter region of Cx26 gene with bisulfite sequencing polymerase chain reaction $(\mathrm{n}=6)$. (A) Representative sequencing diagrams, $(\mathrm{B})$ the subsequently summarized data and $(\mathrm{C})$ total methylated $\mathrm{CpG}$ rates are shown. Methylation is indicated by closed circles and unmethylated $\mathrm{CpGs}$ are indicated as open circles. "P<0.001 vs. control group. Cx26, connexin 26. 
chronic maternal hypoxia increases $\mathrm{CpG}$ site methylation of the promoter region of $\mathrm{Cx} 26$ gene in cochlear tissues of offspring.

\section{Discussion}

The present study aimed to evaluate the effect of chronic prenatal hypoxia on hearing development and the associated mechanisms. Long-term prenatal hypoxia, lasting for 2 weeks preterm, results in hearing dysfunction and deficiency of hair cell development in the cochlea. These alterations were accompanied by downregulation of Cx26 expression and hypermethylation of the promoter region of this gene. These results demonstrate that chronic prenatal hypoxia is harmful to hearing development in an experimental rat model. Promoter region hypermethylation and expression downregulation of Cx26 may underlie the important functional mechanisms.

Prenatal hypoxia may promote fetal growth restriction and induce a series of changes in the neural, cardiovascular, metabolic and endocrine systems of the adult offspring, which are collectively reflected by decreased body weight $(25,26)$. Consistent with these studies, the effect of chronic prenatal hypoxia on fetal hearing was examined in the current study, and a significant decrease in body weight at the neonatal stage (day of birth) was observed in the hypoxia group compared with the control group. However, by adulthood (21- and 56-day), body weights of hypoxia group offspring were restored, and even greater than normoxic offspring. The increased body weight in adulthood may be due to increased liver-weight and body fat deposition (26).

Although hypoxia in adults frequently causes damage to the brain, but not the inner ear, hypoxia in neonates with inadequate blood-inner ear barrier function can cause damage to the inner ear, leading to sensorineural hearing loss and equilibration disorder $(3,27,28)$. During prenatal stage, hypoxia also induces sensorineural hearing loss in the fetus (29). The incidence of sensorineural hearing loss caused by direct damage to the cochlear hair cells of the inner ear is far more frequent and more serious than disorders affecting the external ear or the middle ear (30). Damage to the inner ear includes the degeneration and disappearance of the outer hair cells of the organ of Corti and edematous changes in the stria vascularis in neonates exposed to hypoxia (3). In the present study, inner and outer hair cell defects were observed in the organ of Corti of hypoxia group rats. These hair cell defects support that the hearing loss was potentially caused by chronic prenatal hypoxia.

Cx26 has an essential role in normal neonatal development, postnatal maturation and homoeostasis of the organ of Corti prior to the onset of hearing (31-33). Cx26 is one of the major building blocks of gap junctions in the human cochlea and is widely expressed in the supporting cells of the sensory epithelial and fibrocytes in the spiral ligament and spiral limbus (34). Cx26 establishes connectivity in distinct cochlear compartment and forms hybrid gap junctions with Cx30 (35). Dysfunction of gap junctions caused by mutations in Cx26 and Cx30 accounts for nearly half of all cases of hereditary nonsyndromic deafness cases (36). Overexpression of cochlear Cx26 restores gap junction function in the cochlea of conditional Cx26 knockout mice (37) and completely rescues hearing in Cx30-null mice deafness model (38). Dominant negative Cx26 mutation R75W causes severe hearing loss and postnatal programmed cell death in the organ of Corti (39). Cx26 knockdown causes malformation of the organ of Corti and distinct cell loss (13). The results of the present study demonstrated that $\mathrm{Cx} 26$ protein and mRNA expression were significantly decreased by chronic maternal hypoxia. Combined with the deficiency of hair cell development, the results of the current suggest a key role of Cx26 downregulation in chronic maternal hypoxia-induced hearing loss.

Recent studies have reported that silencing of connexins, including Cx26, may be induced by epigenetic inactivation through aberrant promoter-region methylation. The promoter-region hypermethylation caused Cx26 downregulation at various tissue types, including colorectal carcinomas (18), lung cancer (17), hepatocellular carcinomas (19), and cochleae (12), although other studies showed Cx26 expression was not mediated by methylation in human esophageal cancer cells (40). In the present study, chronic prenatal hypoxia decreased $\mathrm{Cx} 26$ expression in cochlear tissues. When analyzing the two target $\mathrm{CpG}$ clusters of the promoter region of Cx26 (fragment 1 and 2), significantly increased methylation in fragment 1 and 2 was detected in offspring from hypoxia maternal rats compared with the control group. This suggests a negative association between Cx26 expression and hypermethylation. Notably, the number of methylation sites was far more in fragment 1 than in fragment 2 . In previous studies, hypermethylation of fragment 2 was considered to be irrelevant to Cx26 gene repression in human mammary cancer cell lines (41) and in the cochlea of inner ear in mimetic aging rats (12). In the present study, the methylation level of fragment 2 was increased in the hypoxia group compared with the normoxic control group.

In conclusion, the present results demonstrate the harmful effect of chronic prenatal hypoxia on hearing development. Promoter region hypermethylation and subsequent reduced expression of $\mathrm{Cx} 26$ may act as important factors that underlie the functional mechanisms involved.

\section{Acknowledgements}

This study was supported by the Educational Research Project of Fujian Education Department for Young and Middle-aged Teachers (funding no. JA15718), the Key Project of Science and Technology of Quanzhou City (funding no. 2015Z46) and the National Natural Science Foundation (funding no. 81572662).

\section{References}

1. Cristobal R and Oghalai JS: Hearing loss in children with very low birth weight: Current review of epidemiology and pathophysiology. Arch Dis Child Fetal Neonatal Ed 93: F462-F468, 2008.

2. Yuan Y, Zhang X, Huang S, Zuo L, Zhang G, Song Y, Wang G, Wang H, Huang D, Han D, et al: Common molecular etiologies are rare in nonsyndromic Tibetan Chinese patients with hearing impairment. PLoS One 7: e30720, 2012.

3. Koyama S, Kaga K, Sakata H, Iino Y and Kodera K: Pathological findings in the temporal bone of newborn infants with neonatal asphyxia. Acta Otolaryngol 125: 1028-1032, 2005.

4. Hemker SL, Sims-Lucas S and Ho J: Role of hypoxia during nephrogenesis. Pediatr Nephrol 31: 1571-1577, 2016. 
5. Eleftheriades M, Creatsas G and Nicolaides K: Fetal growth restriction and postnatal development. Ann NY Acad Sci 1092: 319-330, 2006.

6. Nishioka N, Nishina H, Yoshida K, Kinoshita K and Ehara Y: Effect of hypoxia on the auditory system of goat fetuses during extrauterine incubation. J Obstet Gynaecol Res 29: 109-114, 2003.

7. Widziszowska A and Namyslowski G: Assessment of hearing organ activity in a group of neonates with central nervous system impairment. Int J Pediatr Otorhinolaryngol 75: 1280-1284, 2011

8. Lee MY, Takada T, Takada Y, Kappy MD, Beyer LA, Swiderski DL, Godin AL, Brewer S, King WM and Raphael Y: Mice with conditional deletion of $\mathrm{Cx} 26$ exhibit no vestibular phenotype despite secondary loss of Cx30 in the vestibular end organs. Hear Res 328: 102-112, 2015.

9. Skvorak Giersch AB and Morton CC: Genetic causes of nonsyndromic hearing loss. Curr Opin Pediatr 11: 551-557, 1999.

10. Lalwani AK and Castelein CM: Cracking the auditory genetic code: Nonsyndromic hereditary hearing impairment. Am J Otol 20: 115-132, 1999.

11. Locke D, Bian S, Li H and Harris AL: Post-translational modifications of connexin 26 revealed by mass spectrometry. Biochem J 424: 385-398, 2009.

12. Wu X, Wang Y, Sun Y, Chen S, Zhang S, Shen L, Huang X, Lin X and Kong W: Reduced expression of Connexin26 and its DNA promoter hypermethylation in the inner ear of mimetic aging rats induced by D-galactose. Biochem Biophys Res Commun 452: 340-346, 2014

13. Chen S, Sun Y, Lin X and Kong W: Down regulated connexin 26 at different postnatal stage displayed different types of cellular degeneration and formation of organ of Corti. Biochem Biophys Res Commun 445: 71-77, 2014

14. Xiong M,Zhu Y,Lai H,Fu X,Deng W, Yang C, He Q and Zheng G: Radix astragali inhibits the down-regulation of connexin 26 in the stria vascularis of the guinea pig cochlea after acoustic trauma. Eur Arch Otorhinolaryngol 272: 2153-2160, 2015.

15. Virmani AK, Muller C, Rathi A, Zoechbauer-Mueller S Mathis $\mathrm{M}$ and Gazdar AF: Aberrant methylation during cervical carcinogenesis. Clin Cancer Res 7: 584-589, 2001.

16. Yano T, Ito F, Kobayashi K, Yonezawa Y, Suzuki K, Asano R, Hagiwara $K$, Nakazawa $H$, Toma $H$ and Yamasaki $H$ : Hypermethylation of the $\mathrm{CpG}$ island of connexin 32, a candiate tumor suppressor gene in renal cell carcinomas from hemodialysis patients. Cancer Lett 208: 137-142, 2004.

17. Shimizu K, Shimoichi Y, Hinotsume D, Itsuzaki Y, Fujii H, Honoki $\mathrm{K}$ and Tsujiuchi T: Reduced expression of the Connexin26 gene and its aberrant DNA methylation in rat lung adenocarcinomas induced by $\mathrm{N}$-nitrosobis(2-hydroxypropyl)amine. Mol Carcinog 45: 710-714, 2006.

18. Sirnes S, Lind GE, Bruun J, Fykerud TA, Mesnil M, Lothe RA, Rivedal E, Kolberg M and Leithe E: Connexins in colorectal cancer pathogenesis. Int J Cancer 137: 1-11, 2015.

19. Tsujiuchi T, Shimizu K, Itsuzaki Y, Onishi M, Sugata E, Fujii H and Honoki $\mathrm{K}$ : CpG site hypermethylation of E-cadherin and Connexin26 genes in hepatocellular carcinomas induced by a choline-deficient L-Amino Acid-defined diet in rats. Mol Carcinog 46: 269-274, 2007.

20. Kane AD, Herrera EA, Camm EJ and Giussani DA: Vitamin C prevents intrauterine programming of in vivo cardiovascular dysfunction in the rat. Circ J 77: 2604-2611, 2013

21. Chen F, Du S, Bian J, You ZB and Wu Y: Chronic hypoxia exposure during pregnancy is associated with a decreased active nursing activity in mother and an abnormal birth weight and postnatal growth in offspring of rats. Horm Behav 61: 504-511, 2012.

22. Livak KJ and Schmittgen TD: Analysis of relative gene expression data using real-time quantitative PCR and the 2(-Delta Delta C(T)) Method. Methods 25: 402-408, 2001.

23. Shimizu K, Hanaoka M, Kato A, Fujii H, Honoki K and Tsujiuchi T: Reduced expression of the E-cadherin gene and its aberrant DNA methylation in hamster pancreatic tumors. Biochem Biophys Res Commun 336: 49-53, 2005.
24. Takai D and Jones PA: Comprehensive analysis of CpG islands in human chromosomes 21 and 22. Proc Natl Acad Sci USA 99: 3740-3745, 2002.

25. Giussani DA, Niu Y, Herrera EA, Richter HG, Camm EJ, Thakor AS, Kane AD, Hansell JA, Brain KL, Skeffington KL, et al: Heart disease link to fetal hypoxia and oxidative stress. Adv Exp Med Biol 814: 77-87, 2014

26. Iqbal W and Ciriello J: Effect of maternal chronic intermittent hypoxia during gestation on offspring growth in the rat. Am J Obstet Gynecol 209: 564.e1-564.e9, 2013.

27. Daniel SJ, McIntosh M, Akinpelu OV and Rohlicek CV: Hearing outcome of early postnatal exposure to hypoxia in Sprague-Dawley rats. J Laryngol Otol 15: 1-5, 2014.

28. Mencher LS and Mencher GT: Neonatal asphyxia, definitive markers and hearing loss. Audiology 38: 291-295, 1999

29. Sohmer H and Freeman S: Hypoxia induced hearing loss in animal models of the fetus in-utero. Hear Res 55: 92-97, 1991.

30. Mazurek B, Haupt H, Georgiewa P, Klapp BF and Reisshauer A: A model of peripherally developing hearing loss and tinnitus based on the role of hypoxia and ischemia. Med Hypotheses 67: 892-899, 2006

31. Chang Q, Tang W, Kim Y and Lin X: Timed conditional null of connexin26 in mice reveals temporary requirements of connexin26 in key cochlear developmental events before the onset of hearing. Neurobiol Dis 73: 418-427, 2015.

32. Sun Y, Tang W, Chang Q, Wang Y, Kong W and Lin X: Connexin30 null and conditional connexin 26 null mice display distinct pattern and time course of cellular degeneration in the cochlea. J Comp Neurol 516: 569-579, 2009.

33. Wang Y, Chang Q, Tang W, Sun Y, Zhou B, Li H and Lin X: Targeted connexin26 ablation arrests postnatal development of the organ of Corti. Biochem Biophys Res Commun 385: 33-37, 2009.

34. Liu W, Boström M, Kinnefors A and Rask-Andersen H: Unique expression of connexins in the human cochlea. Hear Res 250 55-62, 2009

35. Ahmad S, Chen S, Sun J and Lin X: Connexins 26 and 30 are co-assembled to form gap junctions in the cochlea of mice. Biochem Biophys Res Commun 307: 362-368, 2003.

36. Zhang Y, Tang W, Ahmad S, Sipp JA, Chen P and Lin X: Gap junction-mediated intercellular biochemical coupling in cochlear supporting cells is required for normal cochlear functions. Proc Natl Acad Sci USA 102: 15201-15206, 2005.

37. Yu Q, Wang Y, Chang Q, Wang J, Gong S, Li H and Lin X: Virally expressed connexin 26 restores gap junction function in the cochlea of conditional Gjb2 knockout mice. Gene Ther 21: 71-80, 2014.

38. Ahmad S, Tang W, Chang Q, Qu Y, Hibshman J, Li Y, Söhl G, Willecke K, Chen P and Lin X: Restoration of connexin26 protein level in the cochlea completely rescues hearing in a mouse model of human connexin30-linked deafness. Proc Natl Acad Sci USA 104: 1337-1341, 2007.

39. Inoshita A, Karasawa K, Funakubo M, Miwa A, Ikeda K and Kamiya K: Dominant negative connexin 26 mutation R75W causing severe hearing loss influences normal programmed cell death in postnatal organ of Corti. BMC Genet 15: 1, 2014

40. Loncarek J, Yamasaki H, Levillain P, Milinkevitch S and Mesnil M: The expression of the tumor suppressor gene connexin 26 is not mediated by methylation in human esophageal cancer cells. Mol Carcinog 36: 74-81, 2003.

41. Singal R, Tu ZJ, Vanwert JM, Ginder GD and Kiang DT: Modulation of the connexin26 tumor suppressor gene expression through methylation in human mammary epithelial cell lines. Anticancer Res 20: 59-64, 2000

This work is licensed under a Creative Commons Attribution-NonCommercial-NoDerivatives 4.0 International (CC BY-NC-ND 4.0) License. 